
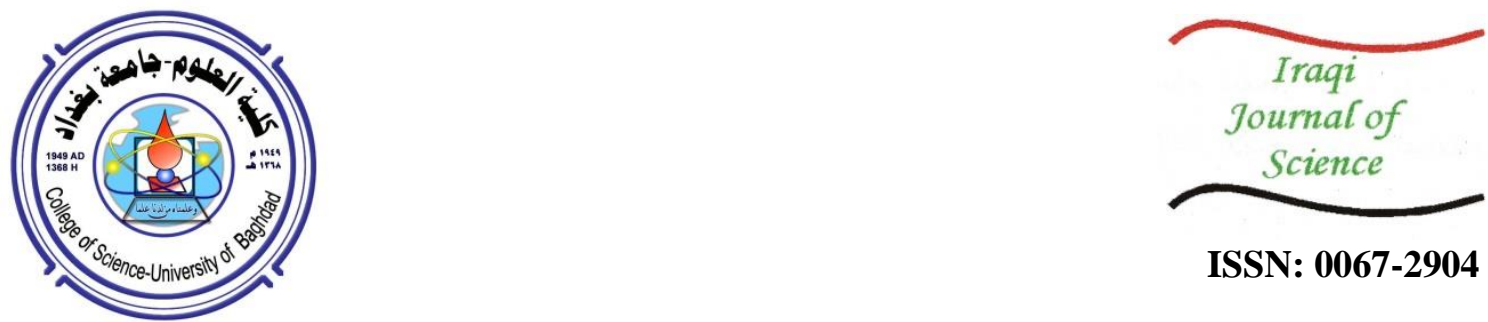

ISSN: 0067-2904

\title{
Effect of Target properties on the Plasma Characteristics that produced by Laser at Atmospheric Pressure
}

\author{
Qusay Adnan Abbas \\ Department of Physics, College of Science University of Baghdad, Baghdad, Iraq
}

\begin{abstract}
In this paper, $\mathrm{Al}$ and $\mathrm{Cu}$ Plasmas that produced by pulsed $\mathrm{Nd}$ :YAG laser with fundamental wave length with a pulse duration of $6 \mathrm{nS}$ focused onto $\mathrm{Al}$ and $\mathrm{Cu}$ targets in atmospheric air are investigated spectroscopically. The influence of pulse laser energy on the some $\mathrm{Al}$ and $\mathrm{Cu}$ plasmas characteristics was diagnosed by using optical emission spectroscopy for the wavelength range 320-740 $\mathrm{nm}$. The results observed that the increase of pulse laser energy causes to increase all plasma characteristics of both plasmas under study and shown increasing of the emission line intensity. The appearance of the atomic and ionic emission lines of an element in the emission spectrum depends on the ionization energy of target atoms. The plasma characteristics are subjected to the ionization energy of the target element and laser energy.
\end{abstract}

Keywords: $\mathrm{Cu}$ Plasma, LIBS, Al plasma, Optical Emission Spectroscopy, Boltzmann plot.

\section{تأثير خواص الهدف على خصائص البلازما المنتجة بالليزر عند ضغط الجوي

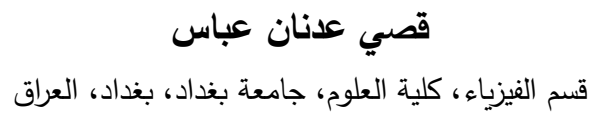

الخلاصة

في هذا البحث , تم استخدام ليزر النيودميوم ياك النبضي ذي طول موجي اساسي وبزمن نبضة مقاره

6nS

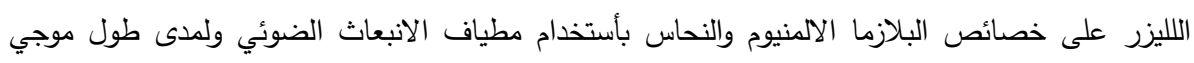

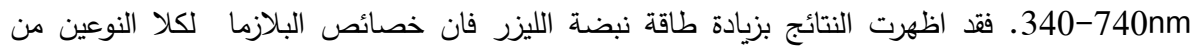

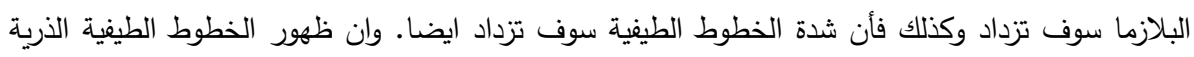

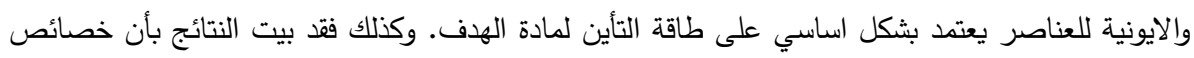

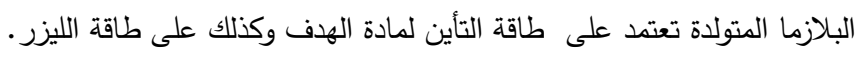

\section{Introduction}

Pulsed laser ablation (PLA) has many applications, making it an attractive area of fundamental research. Some of the PLA applications include laser-induced breakdown spectroscopy (LIBS), laserablation inductively coupled plasma mass spectrometry (LAICPMS), elemental sensors, micromachining, nanomaterial production, pulsed laser deposition (PLD), and light sources for lithography and microscopy [1]. The Laser-Induced Breakdown Spectroscopy (LIBS) technique is one of the techniques used in the elemental analysis field. The basic principle of LIBS is based on an 
exciting matter (gas, liquid, or solid) to plasma state through irradiation by high power laser pulses. The plasma formed, contains atoms and ions in different excited states, radiation, and free electrons. Under the basic assumption that the emitted radiation is influenced by the characteristics of the plasma, hence, it gives a detailed picture of the basic structural elements and different processes can occur in the plasma [2-6].

When a high-power Pulsed laser beam is centralized onto a solid target (laser target), the material will be removed by melting, vaporization, plasma plume formation, sublimation and a number of nonlinear processes. Pulsed laser-induced plasma has a very short temporal existence and transient in nature, with a fast evolution of the characteristic parameters that are heavily dependent on irradiation conditions such as incident laser intensity and irradiation spot size. The characteristics of the plasma plume depend on laser irradiance, target composition, and atmospheric condition. The study of laserinduced plasma behaves a fundamental role for diagnostic purpose in many applications, regarding laser-matter interaction as pulsed laser deposition [7, 8].

The primary aim of this article is to demonstrate the influence of target properties on the plasma characteristics formed by the interaction of pulsed laser with $\mathrm{Cu}$ and $\mathrm{Al}$ targets in the air at atmospheric pressure.

\section{Experimental Set Up}

The LIBS experimental setup is illustrated in Figure-1. Pulse Nd: YAG laser with a fundamental wavelength $1064 \mathrm{~nm}$ and the $6 \mathrm{~ns}$ pulse width were used as a laser source in this system.

The pulsed Nd: YAG laser is focused on a $\mathrm{Cu}$ and $\mathrm{Al}$ targets that located in air at atmospheric pressure by using a convex lens with $10 \mathrm{~cm}$ focal length. Optical emission spectrometer (model THOR Lab) made in Germany is used as a diagnostic tool to determine plasma characteristics by diagnostics of the spatially integrated plasma light emissions that emitted from $\mathrm{Cu}$ and $\mathrm{Al}$ targets surface. The spectrometer was placed at a distance $10 \mathrm{~cm}$ from laser targets and the angle of $45^{\circ}$ from laser beam direction. The results of the spectrum of this system were calibrated with NIST database software to calculate the plasma characteristics.

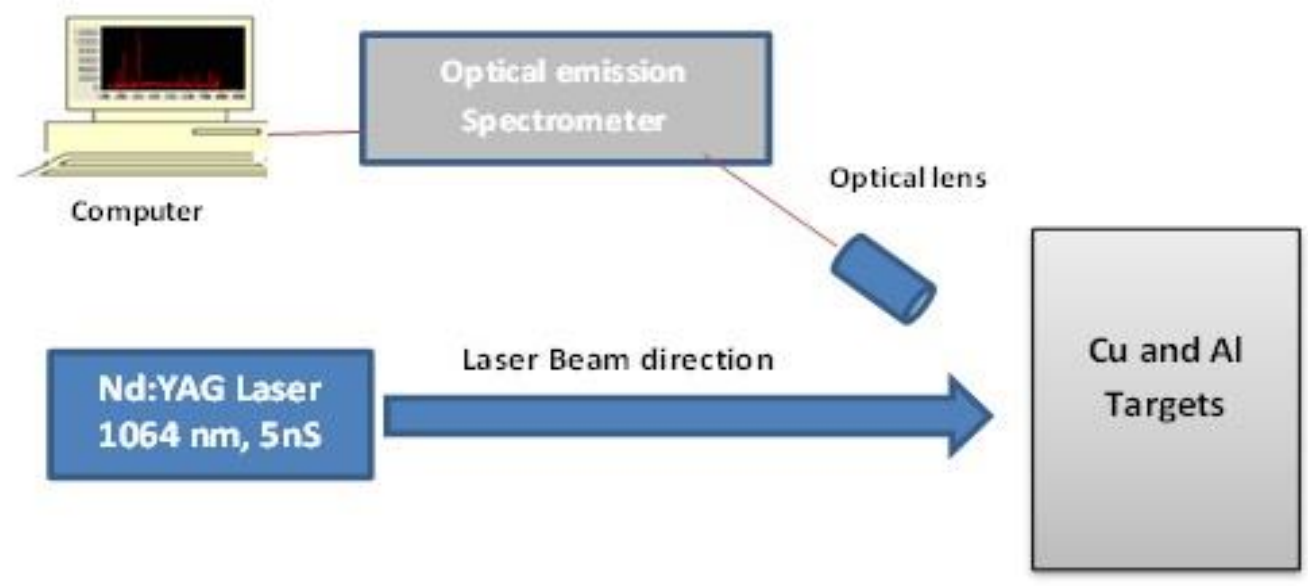

Figure 1: Experimental set up of LIBS.

\section{Theoretical Calculation of Plasma Characteristics 3.1 Electron Temperature}

The electron temperature $\left(T_{e}\right)$ represents one of the most significant parameters used to characterize the plasma state. The determination of $\mathrm{T}_{\mathrm{e}}$ is important to comprehend the excitation, dissociation and ionization processes taking place in the plasma. When the laser light impacts the target surface, the most electrons of the atoms get excited. When the laser energy is more than the binding energy of the target material, evaporation of target material starts by bond breaking occurs. The presence of the plasma plume in front of the target surface deviates the character of the thermal and mechanical effect of laser radiation on the target. In this section, the electron temperature is determined using the Boltzmann plot method from the relative intensities of the observed line, which is ordinarily 
proportional to the population of the pertinent upper levels. The electron temperature can be calculated according to the Boltzmann plot method as [4, 9]:

$$
\ln \left(\frac{I_{Z} \lambda_{k i, Z}}{g_{k, Z} A_{k i, Z}}\right)=-\frac{1}{k_{B} T_{e}} E_{k, Z}+\ln \left(\frac{h c L_{n Z}}{4 \pi P_{Z}}\right)
$$

Where the index $z, k_{B}, h, c, L, E_{k, z}$ and $g_{k, z}$ refers to the ionization state of the species (where $z=0$ and 1 corresponding to the neutral and singly ionized atom, respectively), the Boltzmann constant, The Planck constant, speed of light, the characteristic length of the plasma, the energy and degeneracy of the upper energy level $\mathrm{k}$, respectively. $\mathrm{P}_{\mathrm{Z}}$ is the partition function of the species in ionization stage $\mathrm{Z}$. The integrated intensity $\mathrm{I}_{\mathrm{Z}}$ of a species in ionization stage $\mathrm{Z}$ in optically.

This equation yields a linear plot if one plots the magnitude on the left - hand side for several transitions against the energy of the upper level of the species in ionization stage $\mathrm{Z}$. The electron temperature $\left(\mathrm{T}_{\mathrm{e}}\right)$ can be calculated from the slope of the linear plot.

\subsection{Electron Number Density}

One of the most reliable techniques to determine the electron number density $\left(n_{e}\right)$ is from the using atom and ion spectral lines emitted from the $\mathrm{Al}$ and $\mathrm{Fe}$ plasmas, the electron density is calculated from the Saha-Boltzmann equation as [10]:

$$
\mathrm{n}_{\mathrm{e}}=\frac{\mathrm{I}_{Z}^{*}}{\mathrm{I}_{\mathrm{Z}+1}^{*}} 6.04 \times 10^{21}(\mathrm{~T})^{3 / 2} \times \exp \left[\left(-\mathrm{E}_{\mathrm{k}, \mathrm{Z}+1}+\mathrm{E}_{\mathrm{k}, \mathrm{Z}}-\mathrm{x}_{Z} / \mathrm{k}_{\mathrm{B}} \mathrm{T}\right)\right] \mathrm{cm}^{-3}
$$

where $I_{Z}^{*}=I_{Z} \lambda_{k i, Z} / g_{k, Z} A_{k i, Z}$ And $\mathrm{x}_{\mathrm{z}}$ is the line intensity of the $\mathrm{k}$-i transition and the ionization energy of the species in the ionization stage $Z$, respectively.

\subsection{Plasma Frequency}

The plasma frequency $\left(\omega_{\mathrm{p}}\right)$ which relates to the electron density as [11]:

$$
\omega_{\mathrm{p}}=\sqrt{\frac{\mathrm{e}^{2} \mathrm{n}_{\mathrm{e}}}{\mathrm{m}_{\mathrm{e}} \epsilon_{0}}}
$$

where $\varepsilon_{0}$ is the permittivity of free space, $\mathrm{m}_{\mathrm{e}}$ is the electron mass, and $\mathrm{e}$ is the electronic charge.

\subsection{Debye Length}

The Debye length $\left(\lambda_{\mathrm{D}}\right)$ represents the shielding distance or the thickness of the plasma sheath and can be calculated as [11]:

$$
\lambda_{D}=7430\left(k_{B} T_{e} / n\right)^{1 / 2} m,\left(k_{B} T_{e}\right. \text { in eV) }
$$

where $\mathrm{k}_{\mathrm{B}}, \mathrm{T}_{\mathrm{e}}$ and $\mathrm{n}$ are Boltzmann constant, electron temperature and electron density, respectively.

\subsection{The Plasma Parameter}

The plasma parameter $\left(\mathrm{N}_{\mathrm{D}}\right)$ which represents the number of charged particles in Debye sphere and can be determined as [11]:

$$
N_{D}=1.38 \times 10^{6} T_{e}^{3 / 2} / n^{1 / 2} \quad\left(T_{e} \text { in }^{\circ} \mathrm{k}\right)
$$

\section{Results and Discussion}

\subsection{Influence of Laser Energy on the Emission Spectrum}

In this section, the effect of pulse laser energy on the emission spectrum of $\mathrm{Cu}$ and $\mathrm{Al}$ plasmas of wavelength range 320-740 $\mathrm{nm}$ was investigated in more details.

\subsubsection{Cu Plasma}

The emission spectrum of $\mathrm{Cu}$ plasma of different laser energies at atmospheric air pressure is shown in Figure-2. Many features can be seen in this figure that there are many peaks of neutral copper (Cu I) at the wavelengths of 402.3,406.3, 427.5, 448, 450.8, 453, 453.9, 458.7, 510.5, 515.3, $521.7,529.2,570$ and $578.2 \mathrm{~nm}$ appears in the spectrum. The ionic emission lines of $\mathrm{Cu}$ II also appear at the wavelengths of 422.7 and $467.4 \mathrm{~nm}$. All peaks intensity increasing with increasing of laser energy. In addition, based on the results that indicated in the Figure- 2 that the total intensities of $\mathrm{Cu}$ I emission line is much higher than that of $\mathrm{Cu}$ II. These results indicated the plasma produced containing more atomic $\mathrm{Cu}$ than that of ionic $\mathrm{Cu}$. This fact can be explained as, according to plasma generation process, the ionization processes occur a very short time of less than one millisecond before atomization. Thus, the electrons extruded by atoms during the ionization are farther arrested by ions through the recombination process. Therefore, the ions liberate their energy as photon emission due to recombination. In addition, since $\mathrm{Cu}$ atom has high ionization energy (i.e. it requires high energy to ionize), $\mathrm{Cu}$ atoms have a low possibility to be ionized. 


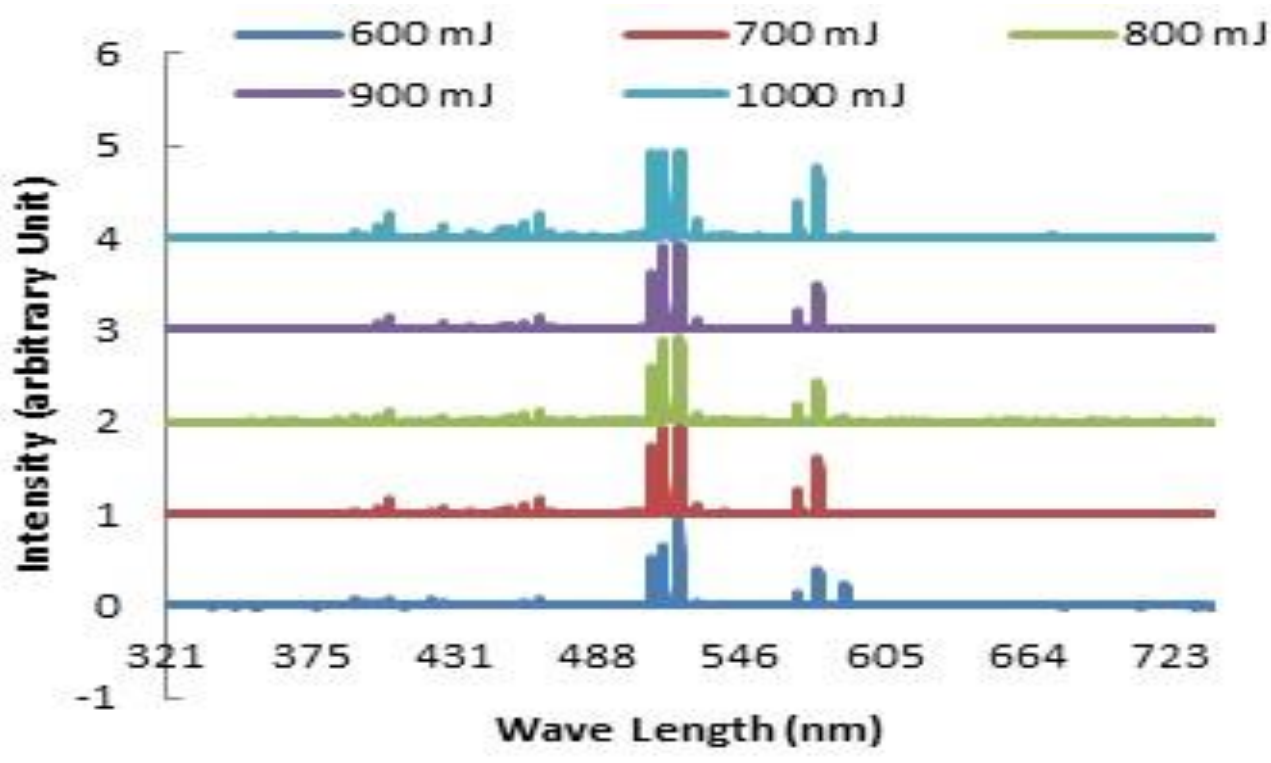

Figure 2-Emission spectra from laser-induced $\mathrm{Cu}$ plasma observed in the region 320-740 nm monitored at time-integrated spectrum $100 \mathrm{~ms}$ for different laser energy at atmospheric pressure in air

\subsubsection{Al Plasma}

The emission spectrum of $\mathrm{Al}$ plasma of different pulse laser energy at wavelength range 320-740 $\mathrm{nm}$ at atmospheric pressure in the air is illustrated in Figure-3. One can observe from this figure that there are many peaks of the neutral Al atom that appear at the wavelengths 394.4, 396.1 and $669.7 \mathrm{~nm}$ in this spectrum. The ionic emission lines of Al II appear at wavelengths 358.7, 466.2, 559.5, 624.3, 683.7 and $704.1 \mathrm{~nm}$. Also, the intensity of all emission lines, increasing with increasing pulse laser energy. According to the results that noted in Figure-3 the total intensities of Al I emission lines are much greater than that of Al II. The emission spectrum of Al plasma showed a more ionic Al than atomic $\mathrm{Al}$. The lower ionization energy of $\mathrm{Al}$ atoms causes to ionize $\mathrm{Al}$ atoms and thus causes for increases in the emission lines of Al II. According to the results in Figures-(2, 3), one can conclude that the appearance of atomic and ionic of any elements in the emission spectrum of the target depends on the ionization energy of target atoms.

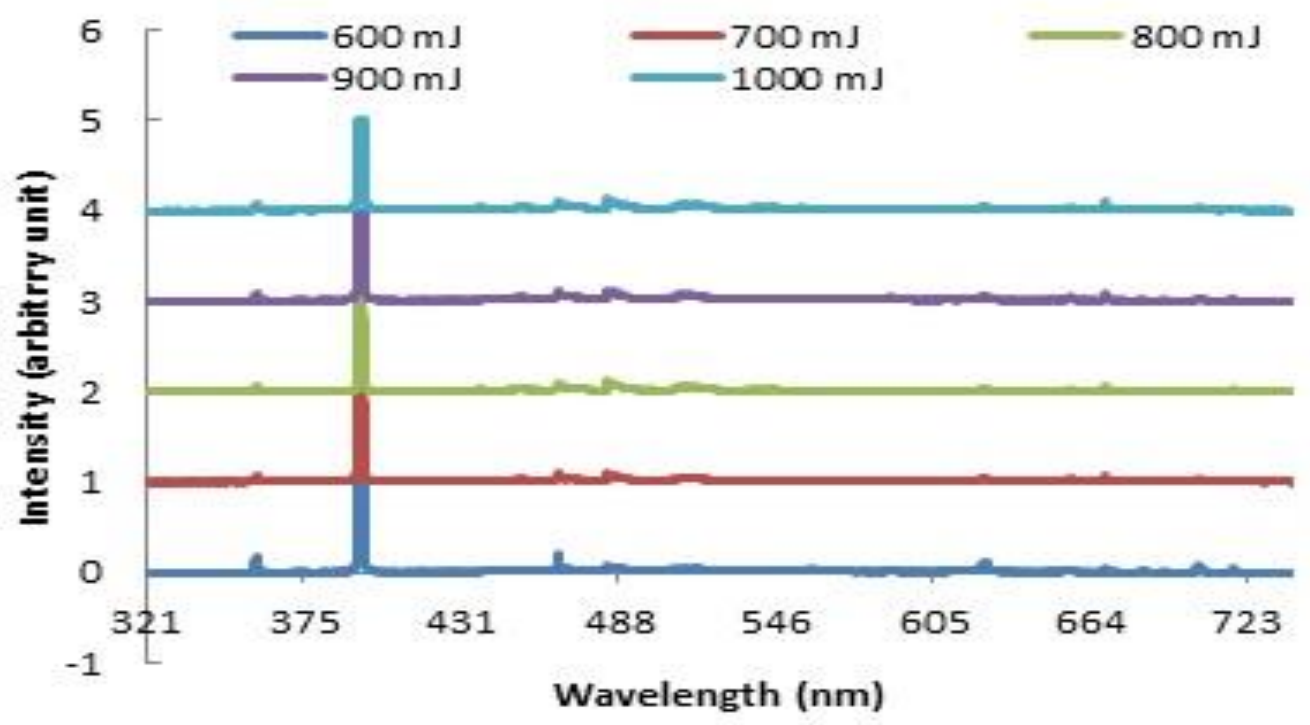

Figure 3-Emission spectra from laser-induced Al plasma observed in the region 320-740 nm monitored at time-integrated spectrum $100 \mathrm{~ms}$ for different laser energy at atmospheric pressure in air. 


\subsection{Influence of Target Metal on the Electron Temperature}

The electron temperature $\left(\mathrm{T}_{\mathrm{e}}\right)$ for $\mathrm{Cu}$ and $\mathrm{Al}$ plasmas that produced by laser in the air at atmospheric pressure can be obtained from the slope of an equation (1). The atomic lines of $\mathrm{Cu}$ I and the ionic lines of $\mathrm{Al} \mathrm{I}$ elements are used to determine the electron temperature at different laser energies $(600,700,800,900$ and $1000 \mathrm{~mJ})$. The parameters of $\mathrm{Cu}$ I and Al II spectral lines are tabulated in the Table-1. Using data that tabulated in the Table-1 and equation (1), the electron temperature was calculated and plotted in Figure-4. Many features can be noted from this figure, the electron temperature of both plasmas increasing with increasing of laser energy. This behavior attributed to the convert of the thermal energy of the laser to the kinetic energy of electrons because of increasing forward peaking with laser energy with constant laser spot size [12]. The value of electron temperature of $\mathrm{Al}$ plasma is greater than that of $\mathrm{Cu}$ plasma under the same conditions. This fact may be due to the ionization energy of aluminum is smaller than that of copper. This fact means that the metals with lower ionization energy causes to increase of Te. This behavior explained as; the metal with low ionization energy have a little amount of energy imparts for the ionization of vapor plume and more convenient energy is valid to heat the plasma.

Table 1-Spectroscopic parameters of $\mathrm{Cu}$ I and Al II that taken from Reference [13]

\begin{tabular}{|c|c|c|c|c|}
\hline Specie & $\boldsymbol{\lambda} \mathbf{( n m})$ & $\left.\mathbf{g}_{\mathbf{k}} \mathbf{A}_{\mathbf{k i}} \mathbf{( \mathbf { s } ^ { - 1 }}\right)$ & $\mathbf{E}_{\mathbf{i}}(\mathbf{e V})$ & $\mathbf{E}_{\mathbf{k}}(\mathbf{e V})$ \\
\hline & 402.2947 & $7.60 \mathrm{E}+07$ & 3.7858976 & 6.8671954 \\
& 406.3067 & $1.26 \mathrm{E}+08$ & 3.816692 & 6.8676455 \\
& 427.5402 & $2.76 \mathrm{E}+08$ & 4.837701 & 7.737027 \\
$\mathbf{6 u} \mathbf{I}$ & 447.9734 & $6.00 \mathrm{E}+06$ & 3.7858976 & 6.55241 \\
& 450.8054 & $5.50 \mathrm{E}+07$ & 5.244851 & 7.993553 \\
& 453.0479 & $1.70 \mathrm{E}+07$ & 3.816692 & 6.55241 \\
& 453.928 & $8.48 \mathrm{E}+07$ & 5.153147 & 7.883492 \\
& 458.6638 & $1.92 \mathrm{E}+08$ & 5.10238 & 7.804589 \\
\hline \multirow{6}{*}{ Al II } & 358.7095 & 358.7581 & $2.12 \mathrm{E}+09$ & 11.846618 \\
& 466.2409 & 466.4361 & $1.74 \mathrm{E}+08$ & 10.598337 \\
& 559.4767 & 559.4855 & $4.63 \mathrm{E}+08$ & 13.25646 \\
& 624.2607 & 624.480 & $9.33 \mathrm{E}+06$ & 13.076729 \\
& 683.7256 & 683.903 & $1.78 \mathrm{E}+08$ & 13.076729 \\
& 704.068 & 704.4 & $2.89 \mathrm{E}+08$ & 11.316596 \\
\hline
\end{tabular}

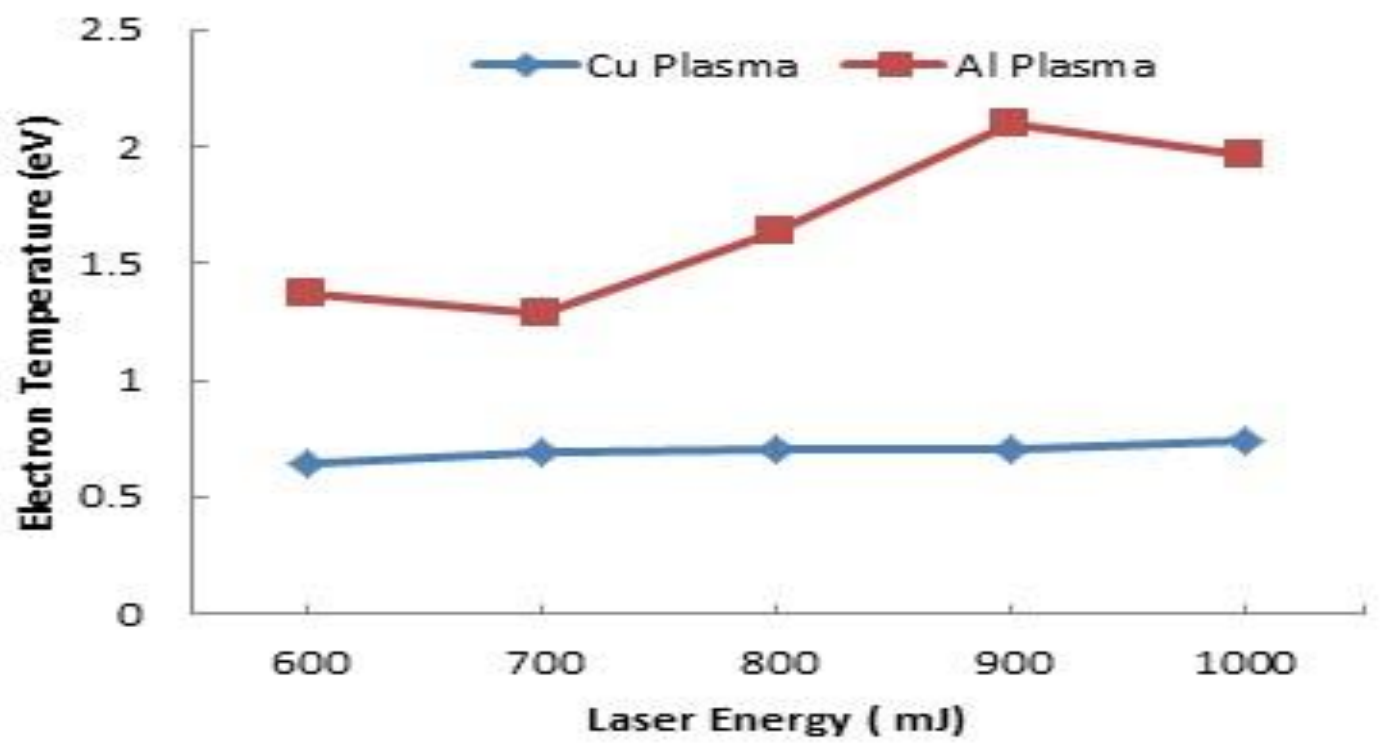

Figure 4-The variation of electron temperature with laser energy in $\mathrm{Cu}$ and $\mathrm{Al}$ plasmas at atmospheric pressure. 


\subsection{Influence of Target Metal on the Electron Density}

According to equation (2) and Table-1, the effect of laser energy on the electron density of $\mathrm{Al}$ and $\mathrm{Cu}$ plasmas is calculated and plotted in Figure-5. It can appear from this figure that the electron density is inversely correlated with the ionization energy of metal targets. Where the electron density of plasma would be greater for smaller the metal ionization potential mainly caused by the mass ablation and consequent denser vapor plasma plume creates higher electron density. The electron density of both plasmas under study is increasing with increasing of laser energy. As well as, the electron density of both plasmas, increasing with increasing of laser energy with the different rate depending on the ionization energy. This increases the electron density with increasing laser energy may be attributed to the absorption of laser photons in plasma by electron-neutral Inverse Bremsstrahlung (IB). As the energy absorbed increases, the excitation temperature and ionization temperature increases and so too does the electron density of the plasma.

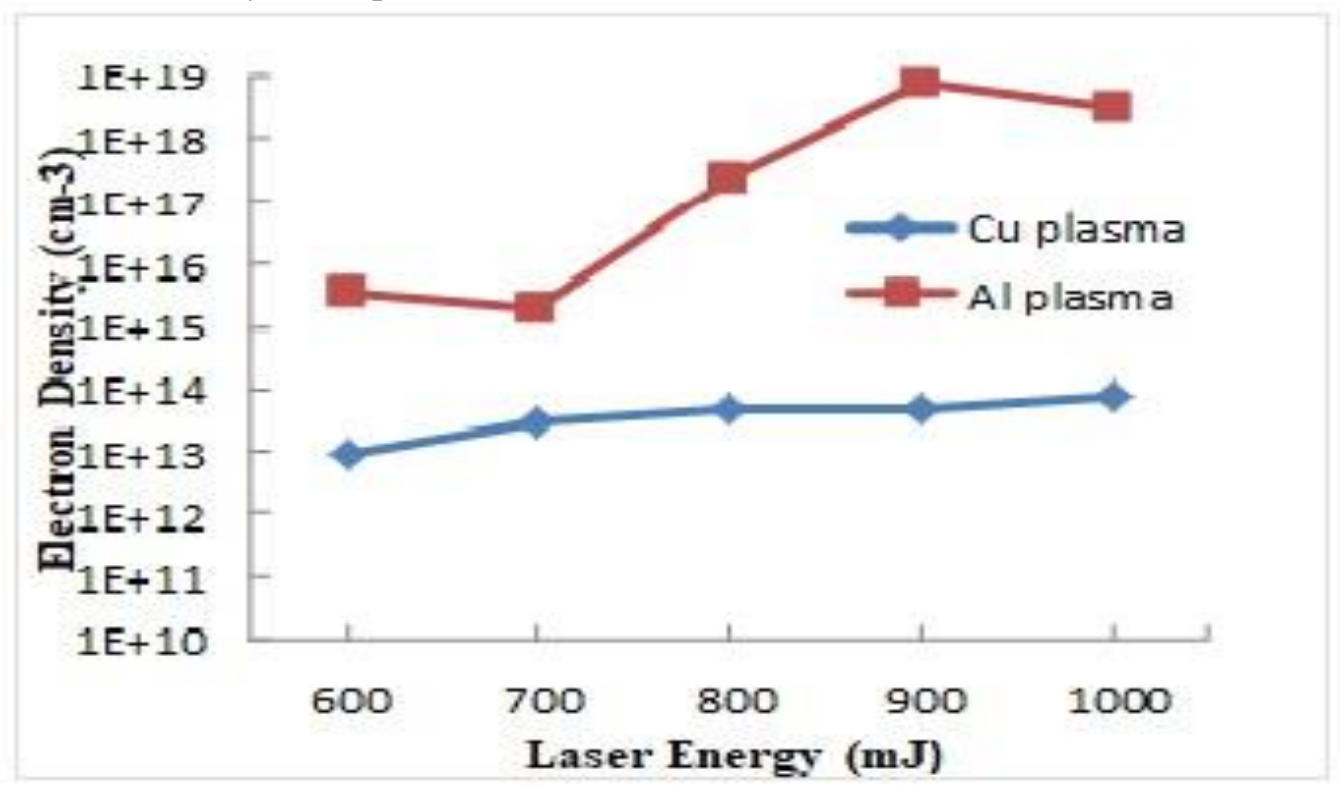

Figure 5-The variation of electron density with laser energy of $\mathrm{Al}$ and $\mathrm{Cu}$ plasmas.

\subsection{Effect of Target Metal on the Plasma Frequency}

Using equation (3) with Figure-5, the variation of electron frequency with laser energy of $\mathrm{Al}$ and $\mathrm{Cu}$ plasmas is drawn in Figure-6. The data points showed in the figure the increasing of the plasma frequency with increasing of laser energy for both plasmas under study. This behavior caused by the increase of the electron concentration with increasing of laser energy which leads to increasing of plasma frequency. The result showed also, the value of the plasma frequency in Al plasma is greater than that in $\mathrm{Cu}$ plasma. This phenomenon attributed to the fact that the electron concentration increased when the ionization energy of the targets was reduced. 


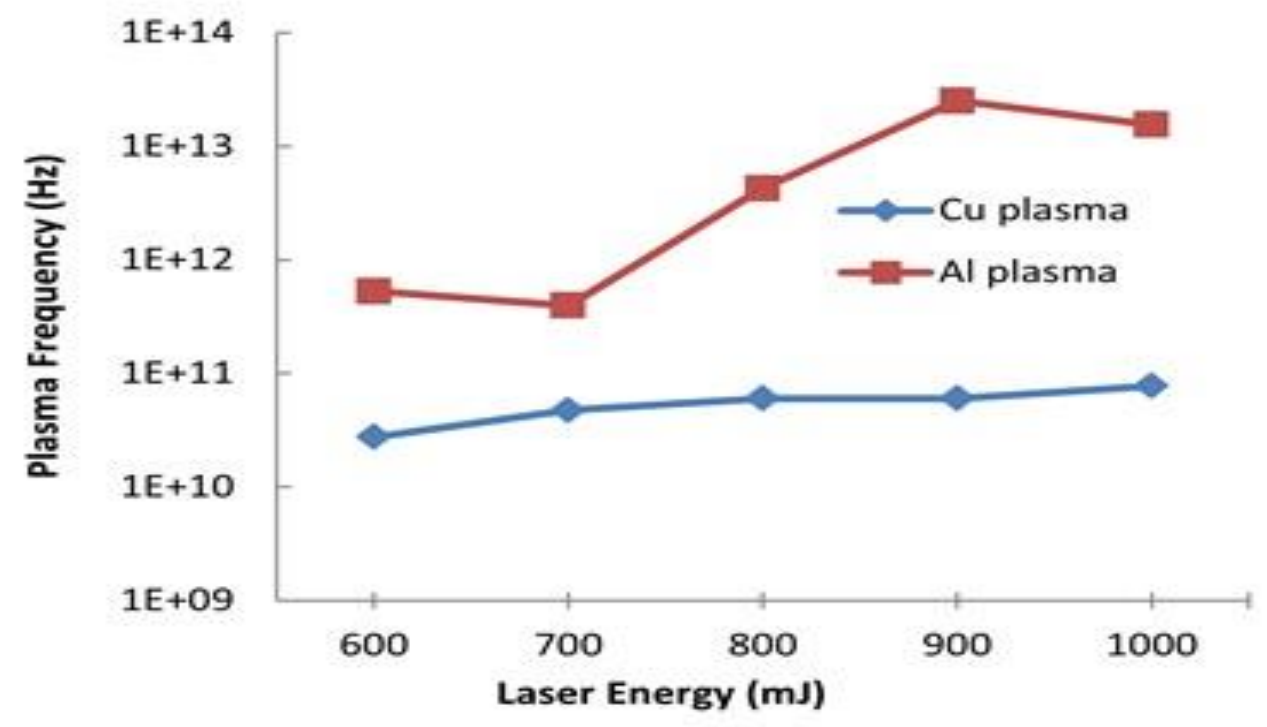

Figure 6-The variation of plasma frequency with laser energy at different target metal.

\subsection{Influence of Laser energy on the Debye Length and Plasma Parameter}

This section describes the effect of laser energy on Debye length and the plasma parameter that calculated by using equations (4) and (5), respectively, after substituting the data of Figures- $(4,5)$. The data that calculated were tabulated in the Table-2. The results indicated that Debye length and plasma parameter reduced with increasing of laser energy. The values of Debye length and plasma parameter of $\mathrm{Cu}$ plasma are greater than of $\mathrm{Al}$ plasma. This behavior of both parameters attributed to the fact that the electron density increase with decreasing of the ionization energy of the target atoms.

Table 2-The influence of Laser energies on Debye length and Plasma Parameter of $\mathrm{Al}$ and $\mathrm{Cu}$ plasmas

\begin{tabular}{|c|c|c|}
\hline \multicolumn{3}{|c|}{ Al Plasma } \\
\hline Laser Energy $(\mathrm{mJ})$ & $\begin{array}{c}\text { Debye Length } \\
(\mu \mathrm{m})\end{array}$ & Plasma Parameter \\
\hline 600 & 14.715 & 46.47 \\
\hline 700 & 19.1085 & 57.01 \\
\hline 800 & 2.0035 & 7.60 \\
\hline 900 & 0.3843 & 1.86 \\
\hline 1000 & 0.6046 & 2.75 \\
\hline \multicolumn{3}{|c|}{ Cu Plasma } \\
\hline 600 & 193.6247 & 285.97 \\
\hline 800 & 116.9056 & 186.18 \\
\hline 900 & 92.5558 & 149.43 \\
\hline 1000 & 92.70557 & 150.49 \\
\hline & 73.8549 & 126.18 \\
\hline
\end{tabular}

\section{Conclusions}

In the present study, we have illustrated the effects of laser energy and properties of laser target on the emission spectra and plasma characteristics of $\mathrm{Al}$ and $\mathrm{Cu}$ plasmas. The present results illustrated that the increase of laser energy shows increasing the emission line intensity for any target. The atomic emission lines were a much greater intensity than that of ionic lines. The appearance of atomic and ionic emission lines for any elements in the emission spectrum of the target depends on the ionization energy of the target atoms.

In addition, the plasma characteristics depend on the ionization energy of the target element and laser energy. 


\section{References}

1. Hussein, A.E., Diwakar, P.K., Harilal, S.S. and Hassanein, A. 2013. The role of laser wavelength on plasma generation and expansion of ablation plumes in air, J. of Appl. Phys. 113: 143305-1.

2. El Sherbini, A.M., Al Amer, A.A., Hassan, A.T. and El Sherbini, T.M. 2012. Measurements of Plasma Electron Temperature Utilizing Magnesium Lines Appeared in Laser Produced Aluminum Plasma in Air, Opti. and Phot. J. 2: 278.

3. Effenberger, A.J. and Scott. J.R. 2010. Effect of Atmospheric Conditions on LIBS Spectra “, Sensors 10: 4907.

4. Abbas, Q.A. 2017. Optical Emission Spectroscopy Study of Fe Plasma at Atmospheric Pressure, PARIPEX - INDIAN J. of Rese. 6: 604.

5. El Sherbini, A.M. and Al Aamer, A.S. 2012. Measurement of Plasma Parameters in Laser-Induced Breakdown Spectroscopy Using Si-Lines, World J. of Nano Scie. and Engi. 2: 206.

6. Zhangy, Y., Zhangyz, J., Pany, S. and Niey, Y. 1997. A Simple Model for Electron Temperature and Penetration Depth in Interaction of Ultra-Short Laser Pulses with Solid Targets, J. Phys. D: Appl. Phys. 30: 655.

7. Qindeel, R., Bidin, N.B. and Mat Daud, Y.B. 2006. The Observation Study of Infrared Laser Induced Plasma Plume", J. of Rese. Science 17(3): 145.

8. MKhater, M.A. 2013. Influence of Laser Pulse Energy on VUV Emission From Laser Plasmas Under Various Ambient Conditions, Rom. J. Phys. 58(2): 181.

9. Hanif, M., Salik, M. and Baig, M.A. 2012. Diagnostic Study of Nickel Plasma Produced by Fundamental $(1064 \mathrm{~nm})$ and Second Harmonics $(532 \mathrm{~nm})$ of an Nd: YAG Laser, J. of Mode. Phys. 3: 1663.

10. Unnikrishinan, V.K., Kamlesh Alti, V.K., Kartha, V.B., Santhoshi, C., Gupta, G.P. and Suri, B.M. 2010. Measurements of plasma temperature and electron density in laser-induced copper plasma by time-resolved spectroscopy of neutral atom and ion emissions, PRAMANA- J. of Phy., 74(6) 983-993.

11. Chen, F.F. 1984. Introduction to Plasma Physics and Controlled Fusion, Plenum Press, New York.

12. Haverkamp, J., Mayo, R.M., Bourham, M.A., Narayan, J., Jin, C. and Duscher, G. 2003. Plasma plume characteristics and properties of pulsed laser deposited diamond-like carbon films, J.of Appl. Phys. 93(6): 3627-3634.

13. National Institute of Standards and Technology (NIST) atomic spectra database, (version 5).

Available at http://www.nist.gov/pml/data/asd.cfm. 